\title{
Covid-19 Impact an Oral Health with a Focus on Temporomandibular Joint Disorders
}

\author{
Joseph Krajekian, ${ }^{1}$ Omar Alkhadra ${ }^{2 *}$ \\ ${ }^{1}$ Board Certified Oral \& Maxillofacial Surgeon, Cleveland Ohio, USA \\ ${ }^{2}$ Registered Dental Hygenist \& Predental student, Cleveland Ohio, USA
}

\begin{abstract}
The Covid-19 pandemic caused an increase in stress-related oral health conditions in 2020. In the United States, at one point the unemployment rate was at $25 \%$ with more than 20 million Americans unemployed. Stressors experienced by the population during 2020 due to Covid-19 were evident in the dental field. This commentary identifies the causes for the spike in stress- related oral conditions as noted by the American Dental Association. Additionally, will explore the cause, effect, and possible solutions of some of the oral-health conditions mentioned.
\end{abstract}

Keywords: Oral health, Joint disorders, Harmful oral bacteria, Tooth chipping

\section{Introduction}

A year after declaring Covid-19 a global pandemic, gathered and analyzed data is starting to show the effects the pandemic had on oral health in the United States. Covid-19 had such a profound impact on all sectors of life because it being a new viral disease that had no treatment and being highly infectious. It had halted life as we knew it, from school and retail shop closures to delaying elective dental procedures for a minimum of 3months. ${ }^{1}$ Before the end of March 2019, 95\% of all dental offices in the US was either completely shut down, or only open for emergency services. ${ }^{2}$ This commentary will focus on the rise of stress-related oral health conditions dental offices have experienced due to the pandemic, with a detailed view on Temporomandibular Joint Disorders (TMJD).

\section{Body}

While the importance of oral health and its relationship to the rest of the body should be already established news with concrete evidence, it is still argued and questioned by some. ${ }^{3}$ The wellbeing of your oral health can influence various disease like:

a) Endocarditis: An infection of the inner lining of the heart occurs when harmful oral bacteria travel through the bloodstream and attach to those areas in the heart. ${ }^{4}$ b) Pneumonia: Harmful bacteria from the oral cavity can travel to the lungs and cause respiratory complications. ${ }^{5}$

c) Pregnancy and birth complication: Periodontal disease has been established as a risk factor for preterm or low birth weight. $^{6}$

Also, in particular situations some disease in the body can affect oral health:

d) Diabetes: due to the reduced immune response, individuals with diabetes and more frequent and more severe gum diseases. $^{7}$

e) HIV: for the same reason as diabetes, individuals with HIV develop painful lesions in their oral cavity. ${ }^{8}$

f) Osteoporosis: a significant periodontal bone loss that leads to tooth loss is prevalent in people with osteoporosis. ${ }^{9}$

Other than the link of diseases between the mouth and the rest of the body, diseases specific to the oral cavity can be severely painful if not debilitating. Dental caries is the most common chronic oral disease in children that very often carries into adulthood. Dental carries have a snowball compounding effect in the mouth. If the car-

\begin{tabular}{|l|l|}
\hline Quick Response Code: & *Corresponding author: Omar Alkhadra, Registered Dental Hygenist \& Predental student, \\
Cleveland Ohio, Tel 888-774-7773, Fax 888-774-7970, USA \\
Received: 24 January, 2021 Published: 09 March, 2021 \\
Citation: Joseph K, Omar A. Covid-19 Impact an Oral Health with a Focus on Temporomandib- \\
ular Joint Disorders. SOJ Den Oral Disor. 2021;1(1):1-5. DOI: \\
10.53902/SOJDOD.2021.01.000505
\end{tabular}


ies is not diagnosed and treated early, they only get worse. A dental cavity can go from being treated with a simple filling to needing expensive multi-step restorative work to save the tooth within the span of 12-months. Periodontal disease is also a common silent disease that can have devastating results in the mouth. Studies show that more than $30 \%$ of Americans have untreated dental caries, and more than $40 \%$ of adult Americans have periodontal involvement. ${ }^{10,11}$

The dramatic life changes experienced by all of us during the pandemic have resulted in an increase in stress-related oral health complications during this past year. ${ }^{12}$ Temporary or permanent loss of jobs, having to care for kids that would otherwise be at school, and juggling home duties while working from home are all stressors that contribute to those complications. According to the Health Policy Institute (HPI) at the American Dental Association (ADA), dentists have seen a significant increase in cases like bruxism (teeth clenching/grinding), chipped teeth, cracked teeth, and TMJD symptoms like headaches and jaw pain ${ }^{13}$ as seen in Figure 1. The two types of bruxism are awake bruxism and sleep bruxism, they are classified based on whether the person has the condition during the day or while they are sleeping. Patients who have sleep bruxism are usually unaware of their condition, which makes them less likely to seek treatment. There is no definitive literature that pinpoints the etiology or treatments of bruxism. Some evidence explains how occlusion and the structure of the jaw bone can affect bruxism.

\begin{tabular}{|c|c|c|c|}
\hline $\begin{array}{l}\text { INCRASED } \\
\text { PREVALENCE } \\
\bullet \bullet \bullet\end{array}$ & $\underset{\text { BRUXISM }}{59.4 \%}$ & $\begin{array}{l}53.4 \% \\
\text { CHIPPED TEETH }\end{array}$ & $\begin{array}{l}53.4 \% \\
\text { CRACKED TEETH }\end{array}$ \\
\hline 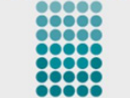 & $\begin{array}{l}53.4 \% \\
\text { TMD SYMPTомS* }\end{array}$ & $\begin{array}{c}26.4 \% \\
\text { CARIES }\end{array}$ & $\begin{array}{c}29.7 \% \\
\text { PERIODONTAL } \\
\text { DISEASE }\end{array}$ \\
\hline
\end{tabular}

Figure 1: ADA health policy data from 2020 Covid 19 Pandemic survey.

Other more common evidence has stress, unhealthy habits like smoking, drinking, lack of sleep, and sleep disorders like apnea and snoring as an etiologic factor for bruxism. ${ }^{14}$ Excessive, untreated bruxism can cause significant enamel wear which results in teeth chipping and cracked teeth. ${ }^{15}$ It can also result in occlusal trauma and inflammation of masticatory muscles which causes migraines. ${ }^{15}$ Knowing this, the findings of the ADA shown in the figure are reasonable. An overall increase in stress levels due to the pandemic resulted in a significant $60 \%$ increase in bruxism cases reported, which in hand resulted in at least some increase in cracked teeth and TMJ problems. The ADA does not explain if the results are directly correlated to bruxism or other unrelated accidents, but given the evidence, it is safe to assume that the increase of those subsequent conditions is related to the increase in bruxism.

The most common solution for bruxism, awake or asleep, is a night guard or an occlusal splint. Over-the-counter mouth guards are one-size-fits-all, and they are made of silicone material. These are usually recommended for awake bruxism because they are less obtrusive and easier to take in and out. While these can help in the prevention of enamel wear, they can still put stress on the TMJ joint and mastication muscles if the person chews on it constantly. Custome fit occlusal splints made at dental offices require an impression mold to be taken and sent to a dental lab to create the split. They are usually made of a hard acrylic material that completely prevents the person from clenching or grinding while being worn. Slight adjustments can be made to the splint by the dentist to ensure a perfect fit for comfortable sleep. Flat plan hard occlusal guard with even occlusion contact is most preferred. Some dentist believes soft splint worsens clenching behaviour.

TMJ problems are even more complicated. The TMJ is the joint between the upper end of the mandible (condyle) and the temporal bone socket (articular fossa) of the skull (Figure 2). The TMJ is a hinge and gliding joint that is responsible for jaw movement and is the most used in the body. The unique feature of the TMJ is the articular disk, which is non- vascular, non-innervated cartilage that sits between both bones. The articular disk's function is to absorb and cushion the constantmovement of the jaw (Figure 3). Anteriorly to the articular disk are the Lateral pterygoid muscles that are used for mastication. Along with the Lateral pterygoid muscle, the temporalis and the masseter muscles are used during bruxism. Posterior to the articulating disk is the retro discal tissue, which is fully supplied with blood vessels and nerves.
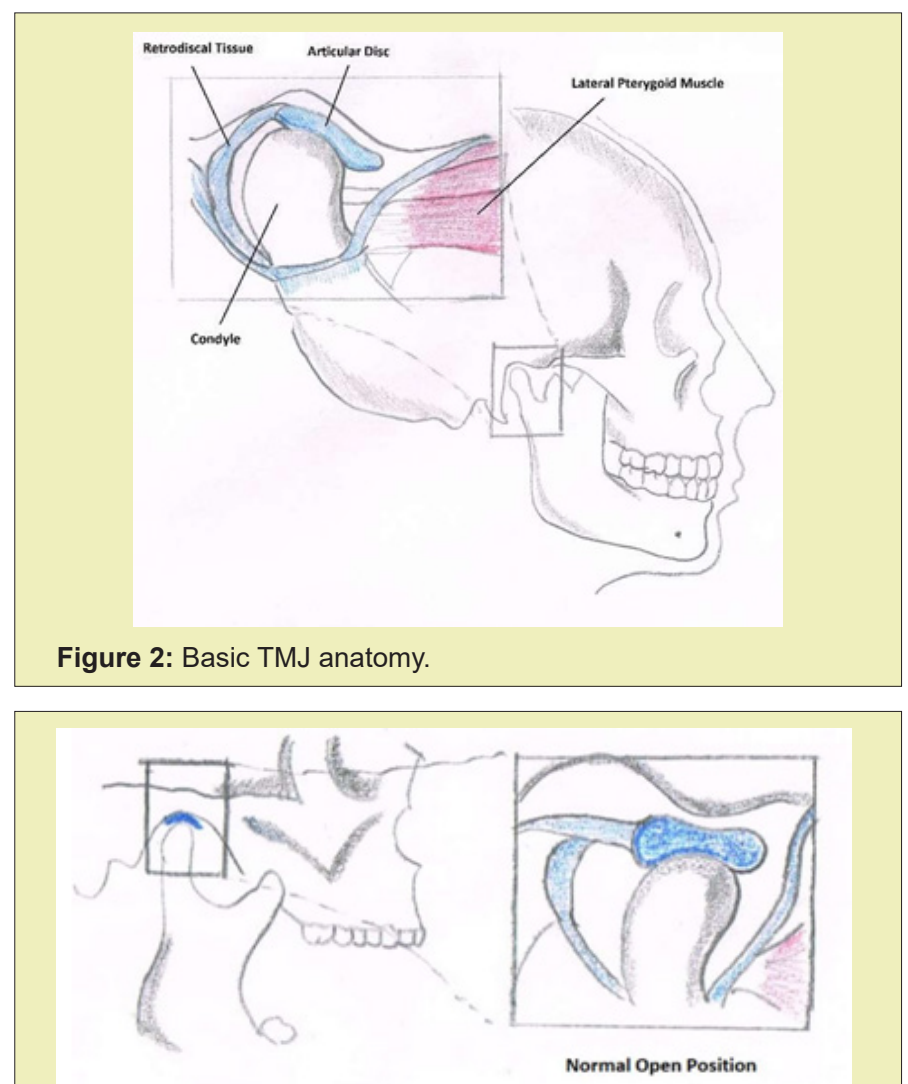

Figure 3: Normal Disc position during open position.

During the first $20 \mathrm{~mm}$ of mouth opening the movement of the condyle inside the fossa is only rotational. When the mouth is opened beyond the first $20 \mathrm{~mm}$ the condyle is moved anteriorly and downwards of the articular eminence, this movement is called 
translation. In healthy translation, the articular disk stays on top of the condyle and moves with it as it glides against the articular eminence as the mouth opens, then returns when the mouth is closed.

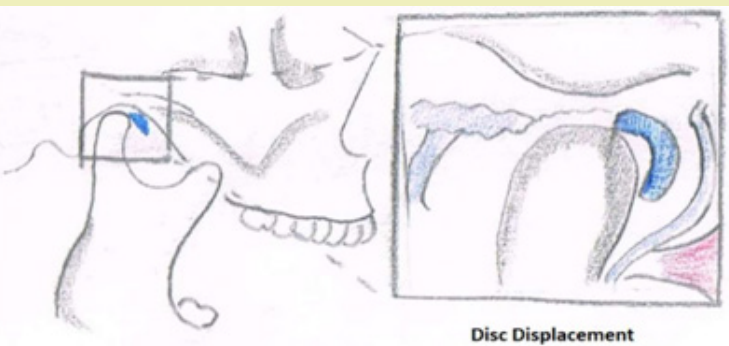

Figure 4: TMJ Disc displacement.

The most common dysfunction of the TMJ is disc displacement (Figure 4), this causes the clicking or popping sounds associated with TMJ. In disc displacement, the articular disc is displaced anteriorly to the condyle and translation occurs against the retro discal tissue instead of the articular disc. Pain arises when this hap- pens because of the vascularise and innervations of the retro discal tissue. Other dysfunctions of the TMJ include inflammation of the muscles surrounding the joint and degenerative diseases like osteoarthritis. Determining the cause of TMJ problems is crucial as it is what guides the treatment. The stressors causing bruxism mentioned above are among the common causes of TMJ problems.

Overall TMJ disfunction can be broken divided into 2 categories (Figure 5). Extra articular disorder and intra-articular disorders. Extra-articular includes parafunctional habits (clenching and burixsm). Intra Articular on the other hand is divided into disc derangement (with and without reduction) and degenerative joint disease (inflammatory and non-inflammatory). Proper diagnosis should identify the proper ethiologies otherwise patient will fail to have complete resolution. Advance imaging like CT scan and MRI might be required to confirm diagnosis in some cases. TMJ has non-invasive and invasive modalities of treatment (Figure 6). The vast majority of TMJ disorders are treated via conservative means like mouth guards, NSAIDs, muscle relaxants, and Botox treatment with over then $85 \%$ success rate.

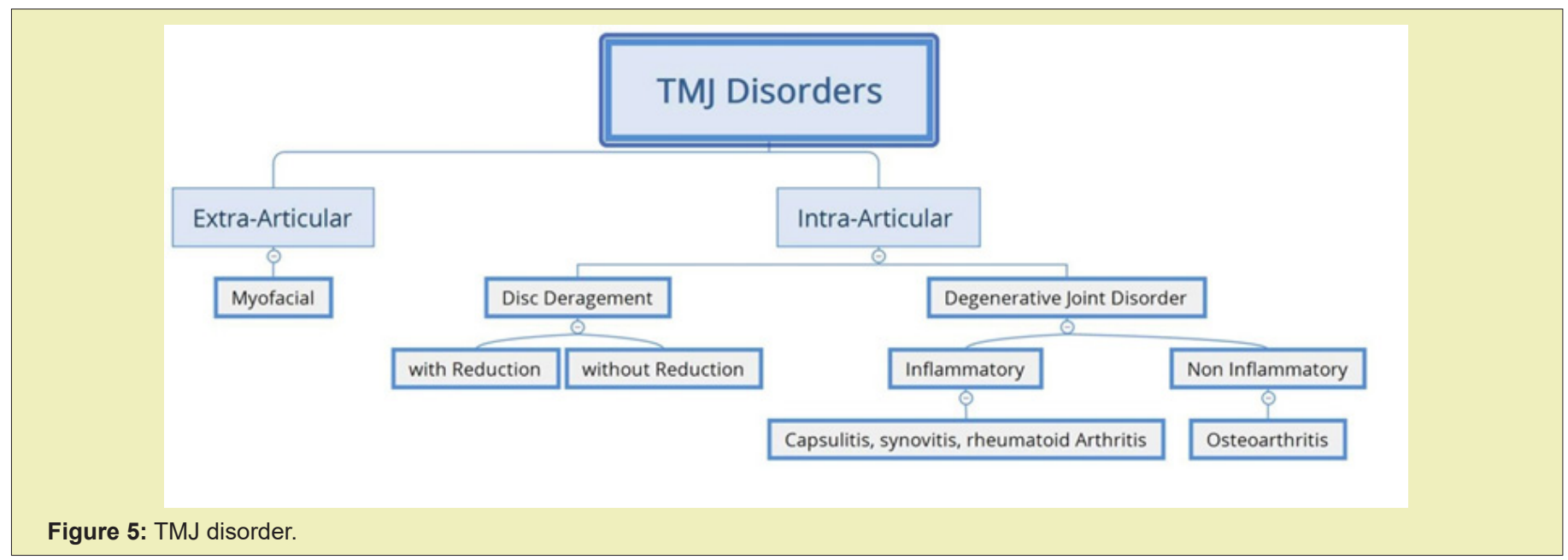

Figure 5: TMJ disorde.

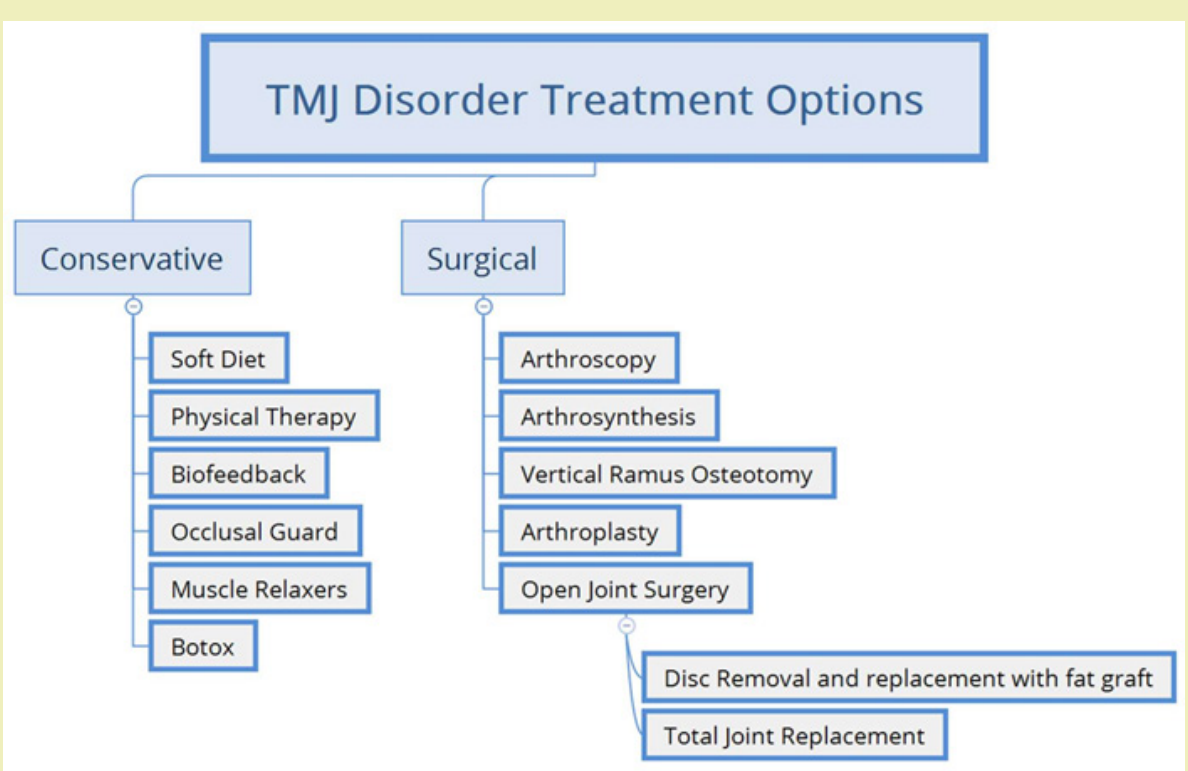

Figure 6: TMJ disorder treatment options. 
Botulinum toxin (Botox) is known to many as the cure for aging, as its mainstream use it to remove wrinkles in the face. In reality, Botox has many therapeutic applications in the medical and dental field. Botulinum toxin is a poison that is produced by a Gram-positive bacterium called $\mathrm{C}$ Botulinum. This bacterium produces 7 strains of the toxin, with toxin A being the most widely used and studies of the group. Its first therapeutic use was discovered by German physician Justinus Kerner, he referred to it as "sausage poi- son" because he noticed illness after eating rotten sausages. Botox works by inhibiting nerve impulses from reaching the muscle by blocking acetylcholine at the neuromuscular junction. The specific use of Botox in the proper dosages and the proper muscle site can aid in relieving many illnesses in the dental field including, chronic migraines, bruxism, mandibular spasms, and trigeminal neuralgia (Figure 7).

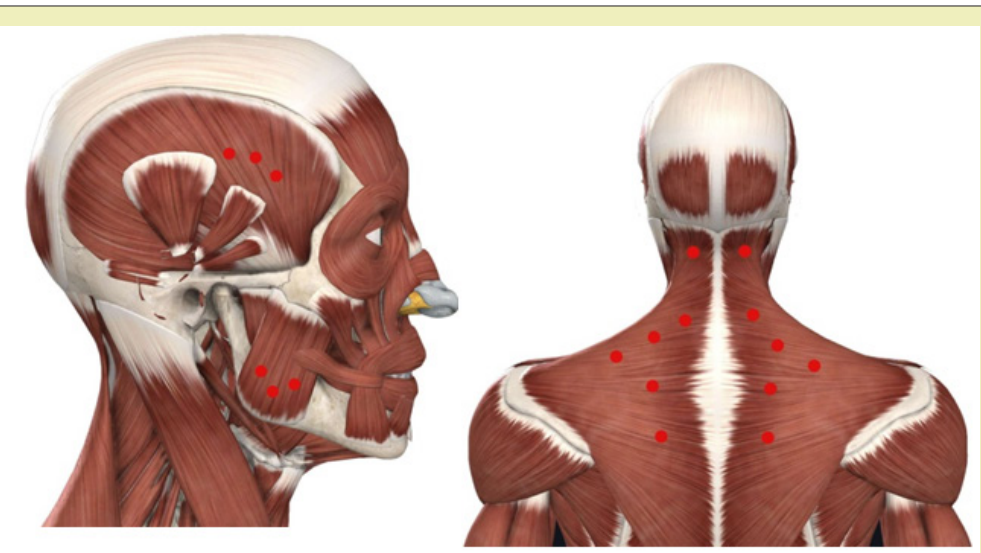

Figure 7: Botox injection pattern (red dots). 100-200 units Images courtesy of Complete Anatomy.

Surgical options of TMJ treatment include:

a. Arthrocentesis: Flushing fluid from the joint and gently stretching it.

b. Arthroscopy: using a miniature telescoping instrument to repair the joint.

c. Arthrotomy: open joint surgery for more complex cases.
One of the preferred TMJ diseaseclassifications is Wilkes. The classification is driven based on clinical and radiographic finding. Wilkes describes disease progression of intra-articular gross pathology of internal derangement and osteoarthritis in the joint. It is useful for disease classification and predicting treatment recommendations. For best surgical results it is emparative that patients are approached in multi-modality fashion (Table 1).

Table 1: Wilkes stages of internal derangement.

\begin{tabular}{|c|c|c|c|}
\hline Stages & Clinical Characteristic & Imaging (CT/MRI) & Treatment \\
\hline Early & $\begin{array}{l}\text { Painless clicking No restricted } \\
\text { motion }\end{array}$ & $\begin{array}{l}\text { Slightly forward disc Normal osse- } \\
\text { ous contours }\end{array}$ & $\begin{array}{l}\text { Conservative treatment with splint therapy and } \\
\text { Botox }\end{array}$ \\
\hline Early/Intermediate & $\begin{array}{l}\text { Occasional painful clicking Inter- } \\
\text { mittent locking Headaches }\end{array}$ & $\begin{array}{l}\text { Slightly forward disc Early disc de- } \\
\text { formity Normal osseous contours }\end{array}$ & $\begin{array}{c}\text { Conservative treatment with splint therapy and } \\
\text { Botox Surgery-arthroscopy Surgery- arthroplas- } \\
\text { ty with fat graft Surgery-mandibular condylot- } \\
\text { omy }\end{array}$ \\
\hline Intermediate & $\begin{array}{l}\text { Frequent pain, joint tenderness, } \\
\text { headaches, locking, restricted mo- } \\
\text { tion, painful chewing }\end{array}$ & $\begin{array}{l}\text { Anterior disc displacement Mod- } \\
\text { erate to marked disc thickening } \\
\text { Normal osseous contours }\end{array}$ & $\begin{array}{l}\text { Conservative treatment with splint therapy and } \\
\text { Botox Surgery-arthroscopy Surgery-arthroplasty } \\
\text { with fat graft Surgery-mandibular condylotomy }\end{array}$ \\
\hline Intermediate/Late & $\begin{array}{l}\text { Chronic pain, headaches Restricted } \\
\text { motion }\end{array}$ & $\begin{array}{l}\text { Anterior disc displacement Mod- } \\
\text { erate to marked disc thickening } \\
\text { Abnormal osseous contours }\end{array}$ & $\begin{array}{c}\text { Surgery-arthroscopy Surgery-arthroplasty with } \\
\text { fat graft Surgery-mandibular condylotomy Sur- } \\
\text { gery-total joint replacement }\end{array}$ \\
\hline Late & Variable pain Joint crepitus pain & $\begin{array}{l}\text { Anterior disc displacement with } \\
\text { disc perforation and gross deformi- } \\
\text { ty Degenerative osseous changes }\end{array}$ & Surgery-total joint replacement \\
\hline
\end{tabular}

\section{Conclusion}

In conclusion, acknowledging the stressors faced in our daily life, especially during this pandemic, is an important first step towards understanding the causes of TMJ dysfunction. Often overlooked causes like bruxism not only cause TMJ problems but also tooth chipping and fracturing which in often cases end up in losing the tooth. The treatment of common TMJ problems is rather simple, like a mouth appliance or a muscle relaxer to reduce stress acting on the joint. If, and when cases do require surgical interference, medicine has evolved tremendously in recent years and the success rates of these surgeries are rather high. The goal of dental health care providers should always be to stay up to date with modern medicine to provide the best quality health care to their patients. 


\section{Acknowledgments}

None.

\section{Funding}

None.

\section{Conflicts of interest}

Author declares that there is no conflict of interest.

\section{References}

1. American Dental Association. ADA recommending dentists postpone elective procedures.

2. American Dental Association. HPI poll examines impact of COVID-19 on dental practices.

3. Healthy mouth, healthy body. The Journal of the American Dental Association. 2006;137(4):563.

4. Lockhart PB, Brennan MT, Thornhill M, et al. Poor oral hygiene as a risk factor for infective endocarditis-related bacteremia. J Am Dent Assoc. 2009;140(10):1238-1244.
5. Ali A El-Solh. Association between pneumonia and oral care in nursing home residents. Lung. 2011;189(3):173-180.

6. Ahmad Haerian-Ardakani, Zia Eslami, Fahimeh Rashidi-Meibodi. Relationship between maternal periodontal disease and low birth weight babies. Iran J Reprod Med. 2013;11(8):625-630.

7. Diabetes \& Oral Health.

8. HIV/AIDS \& Oral Health.

9. Oral Health and Bone Disease.

10. Raul I Garcia, Elizabeth A Kaye, Woosung Sohn, The Healthy Eating Index and coronal dental caries in US adults: National Health and Nutrition Examination Survey 2011-2014. J Am Dent Assoc. 2020;151(2):78-86.

11. Paul I Eke, Gina O Thornton-Evans, Liang Wei, et al. Periodontitis in US Adults: National Health and Nutrition Examination Survey 2009-2014.J Am Dent Assoc. 2018;149(7):576-588.e6.

12. Carey M. HPI Poll: Impact of Covid-10 on Dental Practices. 2020.

13. Vercasi MB. HPI Poll: Dentists See Increase in Patients Stress Related Oral Health Conditions. 2020.

14. Manfredini D, Lobbezoo F. Role of psychosocial factors in the etiology of bruxism. J Orofac Pain. 2009;23(2):153-166.

15. Health ND. Temporomandibular Joint Dysfunction Overview. 2021. 